\title{
Sobre alguns usos emergentes da história oral nos Estados Unidos: o caso do furacão Katrina
}

\section{On some emerging uses of oral history in the US: the case of hurricane Katrina}

Mariana Cavalcanti

Em 22 de abril de 2008, o historiador Ron Grele enviou um e-mail à lista de discussão Oral-Hist - que faz parte da rede H-Net Academic Announcements ${ }^{1}$ e constitui um dos principais fóruns de discussão sobre a história oral no mundo anglo-saxão - declarando sentir-se "enferrujado" (após sua aposentadoria como diretor do Oral History Research Office da Universidade de Columbia, podemos presumir) e pedindo ajuda aos demais membros da lista:

Poderiam listar para mim três títulos de publicações em história oral, publicadas depois de 1990, que considerem mais ou menos seminais para o campo? Podem ser livros, artigos, papers etc., mas, por

Mariana Cavalcanti é professora adjunta do CPDOC/FGV (mariana.cavalcanti@fgv.br).

Artigo recebido em 23 de dezembro de 2008 e aprovado para publicação em 4 de março de 2009.

Estudos Históricos, Rio de Janeiro, vol. 22, nº 43, janeiro-junho de 2009, p. 196-217. 
favor, devem endereçar questões de história oral, não história em geral, nem filosofia, crítica, a vida etc. ${ }^{2}$

Deixemos em suspenso as possíveis críticas a uma certa arrogância que transparece no pedido - por ora, ao menos, pois essa atitude transcende a pessoa de Grele em si e nos ajuda a situar um lugar de fala específico (e próprio de muitos estudiosos da academia norte-americana), ainda que disputado, na paisagem da história oral como um campo de pesquisas internacional. Grele solicitou que as respostas fossem feitas diretamente para ele, e o assunto parecia ter desaparecido de um fórum marcado por longos debates. No entanto, dois dias depois ele ressurge na lista:

Respostas ao meu pedido de obras seminais após 1995 foram parcas. A maior parte daqueles que respondeu, em geral, indicou trabalhos realizados nos anos 70 e 80 , ou de autores que desenvolveram suas ideias neste período e permanecem ativos. Alguns sugeriram trabalhos baseados nas ideias daquele tempo. Talvez eu esteja procurando no lugar errado. Alguém poderia sugerir três páginas de internet seminais que eu deveria consultar, ou performances que eu deveria ver, ou outro tipo de trabalho não impresso que creiam estar redefinindo o campo? Há vida no campo da história oral para além da geração dos anos 60 ?

Quatro dias depois, em 28 de abril, vem uma resposta em público, assinada por John Hopton, da Escola de Enfermagem, Partos e Serviço Social da Universidade de Manchester:

Isto pode ser um tanto tangencial ao que você realmente quer explorar, mas é possível argumentar que o advento da mídia digital e da internet gerou novos meios que podem compartilhar algumas características da história oral, mas que nos demandam novos enquadramentos epistemológicos... Então, com base nisso, eu diria que há, definitivamente, um futuro para a história oral.

Como exemplos desse "futuro", Hopton cita um projeto desenvolvido pela rede de televisão inglesa BBC, apresentado no Congresso de 2006 da Associação de História Oral Inglesa, cujo objetivo era ensinar as pessoas a fazer vídeos autobiográficos, e um artigo de sua própria autoria sobre como usar fontes da internet como história oral. ${ }^{3}$ 
A troca de mensagens é emblemática tanto dos termos do debate atual quanto dos temas prioritários na agenda de pesquisadores que se dedicam a teoria e prática da história oral no mundo anglo-saxão - ao menos aqueles que o fazem com uma atitude reflexiva e uma visão histórica de suas transformações ao longo dos anos. A pergunta de Grele revela o constante esforço de pensar uma historicidade própria do movimento, que simultaneamente atente para suas particularidades dentro do campo mais amplo da história e marque seus diálogos com outras disciplinas, em particular a antropologia, a sociologia qualitativa, a psicologia social. Lembremos que Grele é conhecido no campo, sobretudo, como autor principal do clássico Envelopes of sound ${ }^{4}$ (1985) que, se não inaugura, ao menos se tornou emblemático da incorporação do desconstrucionismo para a reflexão sobre a prática da história oral no mundo anglo-saxão. Influenciado pela teoria althusseriana tão em voga nos anos 1970, no livro Grele define a entrevista de história oral como uma narrativa "conversacional", como um ato "consciente" de historiografia que torna possível vislumbrar as relações do sujeito que fala e da entrevista em si com o mito, a ideologia e a história (Grele, 1985: ix). Celebrado como um dos grandes teóricos da história oral norte-americana, Grele ocupou lugar de destaque na institucionalização do movimento nos Estados Unidos e na fundação da Associação Internacional de História Oral. Nesta última, no entanto, é uma figura controversa, talvez por sistematicamente confundir os caminhos da história oral nos Estados Unidos com sua trajetória global, como se a última fosse dependente da primeira.

Vindo de um Grele aposentado, portanto, a pergunta sobre o futuro da história oral remete tanto às práticas correntes, quanto ao estado atual da reflexão teórica sobre estas (além, é claro, de incluir uma certa provocação sobre como o campo sobrevive sem sua presença). Diante da escassez de novos tratados teóricos, pergunta, então, se mais uma vez a tecnologia transformou radicalmente o que a história oral pode ser.

Já a resposta de Hopton aponta para uma fragmentação dos próprios termos do debate até os anos 1980, ao afirmar que há a necessidade de se pensar novos enquadramentos epistemológicos para "meios" que compartilham características da história oral. Seu e-mail aponta para os novos usos e apropriações desta, que obrigam estudiosos concernidos com questões metodológicas e epistemológicas da prática da história oral a ampliar o horizonte desses diálogos para incorporar questões também do âmbito da comunicação, dos estudos de mídia e dos estudos de performance (em suma, incluindo no debate as dimensões políticas e estéticas da comunicação).

De todo modo, tanto a pergunta de Grele (em última instância, “o que há de novo?”) quanto a resposta de Hopton (“a fragmentação da história oral”) apontam para um crescente consenso que vem se delineando ao longo da última década, que afirma que estaríamos diante de um novo momento na trajetória da 
história oral, em que a tecnologia e as novas mídias constituiriam agentes fundamentais a determinar o(s) tipo(s) de trabalho(s) e as concepções subjacentes de história oral norteando práticas e usos (cf., por exemplo, Thomson, 2007; Sharpless, 2006). Ora, a relação da história oral com diferentes mídias é uma questão constitutiva do campo, que de certa forma assegura sua continuidade e expansão, constituindo, inclusive, condição de possibilidade para sua visibilidade mais ampla (ou sua "vulgarização", para usar os termos de Michel Trebisch, 1994), como atesta o caso de best-sellers tais como Roots ou Division Street America. ${ }^{5} \mathrm{Ou}$ seja, não há ortodoxia possível para a prática da história oral, sobretudo quando esta passa a ser acolhida em projetos cada vez mais díspares, como discutirei a seguir. Assim, o que importa aqui é menos discutir se estamos ou não diante de um novo momento na trajetória da história oral do que tomar essa ideia de uma nova era como uma "representação nativa" acerca da teoria, metodologia e prática da história oral nos Estados Unidos, que nos fornece um ponto de partida para pensar seus usos e apropriações emergentes.

Em particular, o meu intuito neste artigo é discutir dois aspectos da utilização das novas mídias para a produção e disseminação de testemunhos concebidos como história oral por aqueles que os produzem nos Estados Unidos hoje. O primeiro aspecto é mais político, e diz respeito às apropriações contemporâneas da história oral para a construção política de memórias (e, consequentemente, de silêncios) deliberadamente produzidas tendo em vista a consolidação de narrativas hegemônicas futuras. Esse uso é particularmente visível em projetos que utilizam a história oral para dar voz às vítimas ou registrar o testemunho de pessoas afetadas por grandes eventos catastróficos recentes, em particular os atentados terroristas de 11 de Setembro e a devastação causada pelo furacão Katrina em Nova Orleans - sendo os usos da história oral em projetos relacionados a este último o objeto de análise deste trabalho. $O$ segundo aspecto da imbricação entre história oral e as novas mídias que quero elaborar aqui diz respeito à própria proliferação de iniciativas que visam dar voz às vítimas de catástrofes. Na análise, o que em princípio pode parecer constituir uma questão de ordem técnica se torna, em si mesmo, um problema de ordem teórica e metodológica - a saber, o excesso de informação e a impossibilidade de sua recuperação - cuja elaboração vem, inclusive, sendo explorada de modo mais genérico no campo da comunicação e das novas mídias (cf., por exemplo, Vaz, 2004).

\section{Nova era ou novos usos?}

Como já afirmado, importa menos discutir se estamos ou não, de fato, diante de uma nova era na prática da história oral. O que importa é tomarmos essa ideia como uma representação que é compartilhada por certos atores sociais 
e que produz, portanto, seus próprios efeitos de realidade. Declarações de rupturas, anunciando "novas eras" ou "novos momentos" de práticas sociais tendem a produzir novos olhares sobre o passado destas. $\mathrm{O}$ caso da história oral norte-americana não é exceção. O consenso de estarmos no limiar de um novo momento da história da história oral tem precipitado uma releitura de seu passado. E é esta releitura que vale a pena destrinchar analiticamente, como sintoma das questões e de alguns dilemas que podemos apontar como emergentes nesses novos usos e apropriações.

De fato, desde os anos 1990, diversos artigos vêm analisando historicamente os efeitos do salto em termos de capacidade de armazenamento e disseminação ocasionado pelas novas mídias, em particular, a crescente acessibilidade econômica dos meios necessários para a produção de fontes em uma escala massiva. Algumas dessas releituras são particularmente interessantes por constantemente entrelaçarem questões teóricas, éticas, práticas e técnicas. ${ }^{5}$ Assim, vale a pena realizar rapidamente uma síntese dos pontos comuns de tantas releituras do passado recente da história oral norte-americana, por dois motivos. Em primeiro lugar, por situar a própria historicidade e temporalidade particulares aos discursos sobre a prática da história oral no mundo anglo-saxão em geral e nos Estados Unidos em particular. Ou seja, essa recapitulação permite restaurar um certo lugar de fala, ou discurso "nativo" dos acadêmicos que trabalham com e pensam a história oral, iluminando, portanto, como essas transformações vêm sendo pensadas por um certo mainstream da academia americana que se coloca a tarefa de pensar a trajetória própria da história oral levando em consideração seus vários usos e apropriações ao longo do tempo. Em jogo, portanto, estão (re)formulações de questões caras e quiçá já clássicas ao campo, tais como as relações entre teoria e prática, ou entre militância e academia. $\mathrm{O}$ segundo motivo para a minha breve retrospectiva é que esta oferece a ocasião de introduzir um lugar de fala outro, de "fora". Interpelar as práticas atuais de uma perspectiva exterior permite um estranhamento sobre alguns aspectos tidos como dados e, como tais, não problematizados pelos atores em questão.

De modo muito breve e seguindo o recente artigo de Alistair Thomson (2007a) como fio condutor (porém incorporando dados e questões levantados pelos já citados Sharpless, Gluck, Ritchie e Eynon, 1999), essa narrativa em vias de consagração situa o início do movimento no pós-guerra, em grande medida facilitado pelo desenvolvimento de gravadores portáteis, mas também do que Thomson chama de "renascimento" da memória como fonte válida e legítima de estudos históricos. Esse "renascimento" teria dado origem ao primeiro programa acadêmico de história oral, sediado na Universidade Columbia, em 1948, a partir de entrevistas com membros do sexo masculino da elite branca. O próprio fato de assinalar o gênero e a classe social dos entrevistados marca uma distância 
dos autores de recentes retrospectivas em relação a essa abordagem, colocando-a como uma pré-história do presente. As retrospectivas tendem a frisar os princípios da atividade na Inglaterra, onde entrevistas com membros da classe operária e de outras minorias são mais celebrados como contribuindo para o movimento da história vista de baixo que marcaria a historiografia dos anos 1960 e 70 . Esse silêncio em relação aos primórdios do movimento em Columbia é por si só representativo do movimento teleológico dessa narrativa emergente sobre a trajetória da história oral que situa o momento atual como mais democrático, no sentido de assinalar o potencial libertador da história oral ao dar voz a grupos historicamente marginalizados que hoje têm a possibilidade de construir sua própria memória coletiva. Retornarei e problematizarei essa premissa em breve.

Seguindo o raciocínio de Thomson, no entanto, passemos ao segundo momento - ou "mudança de paradigma", que é o termo utilizado pelo autor para nomear tais rupturas. Esse segundo momento, ao qual se refere como "abordagens pós-positivistas à memória e à subjetividade", encontra nos textos clássicos de Luisa Passerini (1987) sobre as memórias italianas do fascismo e o trabalho de Alessandro Portelli (1991) sobre a especificidade da história oral seus exemplos paradigmáticos. Nessa fase, o movimento da história oral afirmaria sua diferença ao teorizar a oralidade, a forma narrativa, a subjetividade, a credibilidade "diferente" da memória e a relação entre entrevistador e entrevistado como objetos de teorização e de afirmação de sua singularidade como metodologia. É nesse momento, ainda, que podemos situar Envelopes of sound, de Ronald Grele, cuja intervenção na lista de discussão sobre o futuro da história oral abriu o presente artigo.

O movimento de afirmação da história oral renderia ainda mais frutos no terceiro momento ou "paradigma", em que esta passa a gozar de uma relevância até então inédita como instrumento político nos anos 1980 e sobretudo nos anos 1990 - ou melhor, no que Thomson chama de "era biográfica", quando também situa sua crescente internacionalização, e frisa o papel da América Latina. Esse é, sem dúvida, um movimento típico da visão de mundo anglo-saxã, em particular norte-americana, na medida em que pressupõe que uma história oral "periférica" só entra em cena a partir do momento em que o "centro" toma conhecimento de sua existência. ${ }^{6}$ Por "era biográfica" ele se refere aos usos recentes da memória para a militância e o "empoderamento" de grupos historicamente marginalizados, bem como ao novo lugar de legitimidade do testemunho, seja em conflitos de terras indígenas ou aborígines na Austrália, seja nas comissões de verdade e reconciliação após os regimes militares, o apartheid sul-africano e outros regimes ditatoriais.

Vale a pena intervir aqui nesta narrativa em vias de tornar-se "consagrada" para frisar que, longe de constituir uma singularidade da história oral, essa nova politização da memória, e em particular da memória das vítimas - de geno- 
cídios, de regimes políticos, de formas históricas de marginalização - faz parte de um movimento mais amplo - "global" mesmo - de politização de identidades e, sobretudo, de seu reconhecimento (cf., por exemplo, Taylor, 1992; Brown, 1995) - tema ao qual retorno em breve.

Assim, na narrativa de nossos "nativos" anglo-saxões, há uma tendência a diferenciar, ao menos analiticamente, essa "era biográfica" do que seria uma quarta mudança de paradigma, representada pela chamada "revolução digital". Esta última é comumente descrita em termos da justaposição de dois processos interligados. De um lado, a disseminação tanto de equipamentos e novas mídias, agora disponíveis em escala massiva e a preços acessíveis, o que sem dúvida tem impacto sobre um tipo de produção de conhecimento cuja trajetória é historicamente e inextricavelmente associada à das tecnologias de comunicação e informação. A chamada revolução digital permite a proliferação de usos e linguagens que são incorporadas à própria metodologia e pela prática da história oral - ainda que não sem disputas ou debates. De outro lado, testemunhamos, nos EUA, uma disseminação e proliferação também de projetos comunitários, baseados em memórias comunitárias. A emergência e proliferação dessas memórias locais é um fenômeno que extrapola o campo da história oral; na realidade é discernível em todo o campo de práticas e meios relacionados à memória, que se conecta à já referida politização de identidades no mundo contemporâneo (cf., por exemplo, Huyssen, 2000; Sarlo, 2007).

Isso chama a atenção para outra questão metodológica que concerne às relações diretas de causa e efeito implícitas em grande parte das narrativas sobre este fenômeno: ao se atribuir a proliferação de projetos de história oral ao mero desenvolvimento de certas tecnologias, corre-se o risco de cair na armadilha de um certo determinismo tecnológico fácil (uma discussão consagrada no campo de estudos das novas mídias, cf., por exemplo, Smith e Marx, 1994; Pereira, 2006). É claro que o modo como esses processos se desdobram não pode ser reduzido a ponto de eles serem interpretados como função de uma história diretamente dependente de suas condições tecnológicas. Os usos também dependem de imaginários e práticas sociais que têm historicidades próprias. Em outras palavras, a proliferação de projetos com o objetivo de (re)construir ou reforçar memórias locais ou comunitárias não é derivada necessariamente da dita "revolução digital", ainda que encontre nesta última um fator potencializador - até porque, no caso dos Estados Unidos, era uma tendência que poderia ser verificada desde ao menos os anos 1960 e certamente a partir dos anos 1970 (cf., por exemplo, Trebisch, 1994). Desse modo, é preciso indagar por que esses usos em particular quando tantos outros seriam possíveis. 
Ainda que a afirmativa acima pareça banal, ela desestabiliza as relações de causa e efeito fáceis, estabelecidas na narrativa consagrada sobre o impacto da dita "era digital" sobre a prática da história oral. Desta perspectiva, portanto, a divisão entre a dita era biográfica e a revolução digital perde o sentido. Seria mais profícuo compreender a justaposição desses processos através de análises advindas do campo da comunicação, que elaboram o papel das novas mídias na redefinição das fronteiras outrora estabelecidas entre público e privado. Ou seja, a dita "era biográfica" é também possibilitada e constituída por novas tecnologias de produção e disseminação de imagens e textos, como câmeras digitais, blogs, reality shows, e uma pletora de projetos multimídia disponíveis online. Paula Sibilia $(2003,2008)$, por exemplo, vem desenvolvendo o argumento de que o advento de mídias tais como blogs e webcams constituem os meios através dos quais se expressa uma certa "ênfase biográfica" que permeia o mundo ocidental contemporâneo, reconfigurando as fronteiras outrora nítidas entre o público e o privado, outrora implicadas pela escrita de si dos diários íntimos, por exemplo (ver também Jelin, 2002: 98-9).

A esse argumento, que incide sobre a produção de subjetividades no mundo contemporâneo e opera a partir de uma perspectiva da interioridade psicológica, eu acrescentaria outro, de ordem sociopolítica: a politização de identidades outrora tidas como privadas, que no mundo contemporâneo passam a constituir o objeto de disputas no espaço público (através de acusações de racismo, sexismo, homofobia, entre outros termos que constituem a própria paisagem semântica do multiculturalismo como projeto), tende a fixar posições de vítimas e algozes, constituindo o presente como lugar da reparação de vitimizações históricas e constituindo a figura da vítima (e seu testemunho) como lugar de fala sempre legítimo (e sua fala em si como processo de cura e reparação). ${ }^{7}$

Uma segunda conexão fácil, mas enganosa, que emerge das releituras recentes da história da história oral, diz respeito à constante reiteração sobre a discrepância entre uma história oral produzida pela academia e aquela mais militante. Thomson, Sharpless e os demais historiadores da história oral no mundo anglo-saxão argumentam que a proliferação e/ou democratização da história oral nesse sentido causa uma distância maior entre a sua versão acadêmica - cada vez mais reflexiva - e a prática generalizada, comunitária - cada vez mais imbuída da ideia e do ímpeto de dar voz a todos, sobretudo a grupos historicamente marginalizados e estigmatizados.

Gostaria apenas de sugerir que essas fronteiras não são tão rígidas assim. É certo que esse movimento de aceitação cada vez mais ampla, e a apropriação da história oral por instâncias até aqui inéditas, bem como a visibilidade ampliada proporcionada pela internet e pelas mídias eletrônicas têm efeitos concretos também sobre a sua prática pela academia. Não resta dúvida que há uma deman- 
da crescente por profissionais que dominem tanto os aspectos práticos quanto as minúcias tecnológicas, para atuar nos muitos programas e projetos mais amplos que envolvem a história oral. Basta consultar os sites de associações de história oral, ou os arquivos da própria lista de discussão mencionada no início deste artigo, para que verifiquemos uma pletora de chamadas de oficinas, mini-cursos e outras oportunidades de treinamento e especialização. Talvez ainda mais significante seja a inauguração de dois novos mestrados acadêmicos em história oral no mundo anglo-saxão - o primeiro na Universidade de Columbia ${ }^{8}$ e o segundo na Monash University, na Austrália. Finalmente, como discuto mais à frente, uma série de projetos que utilizam a história oral dentro do ambiente acadêmico norte-americano não apresenta características básicas através das quais reconheceríamos projetos de pesquisa - tais como descritos por Alberti (2004) - que utilizam a metodologia da história oral como fonte principal de suas pesquisas. De outro lado, projetos que se inscrevem em um contexto francamente "militante" se aproximam mais das premissas acadêmicas, o que gera também uma porosidade cada vez maior dessas fronteiras que por tanto tempo foram objeto de debate no campo - e não só no mundo anglo-saxão.

\section{Catástrofes online: "You Tubes" de vítimas}

Um exemplo claro dessa interpenetração entre a história oral acadêmica e a dita "militante" pode ser verificado através de uma busca do tipo de projetos em andamento em grandes e prestigiosas universidades norte-americanas. Uma primeira busca revelou o que me pareceu, inicialmente, uma curiosidade: várias universidades engajadas em projetos ligados à memória dos atentados terroristas de 11 de Setembro, iniciados logo após o acontecimento. Por exemplo, o financiamento do projeto do American Social History Project, sediado na City University of New York (CUNY) foi anunciado já em fevereiro de 2002, e as entrevistas começaram ainda no primeiro semestre daquele ano. Também ainda em 2002 o mesmo Programa de História Oral da Universidade de Columbia começou a desenvolver cinco subprojetos sobre os atentados, seja da perspectiva de moradores, parentes de vítimas, agentes de saúde, e o que veio depois.

A rapidez dessas iniciativas contrasta com a morosidade das discussões em torno do projeto arquitetônico e do memorial permanente em homenagem às vitimas. De imediato, apenas um consenso foi rapidamente atingido - o de que cada vítima teria de ser lembrada individualmente, e nomeada. ${ }^{9}$ Não surpreende, portanto, que antes mesmo da aprovação de qualquer projeto arquitetônico, se tivesse instituído uma cabine que recolhia depoimentos de história oral dos parentes das vítimas em pleno ground zero. ${ }^{10}$ 
Isto, por si só, já ilustra a nova centralidade da história oral para práticas memorialistas em tempos em que o reconhecimento de vítimas (e de sua individualidade, de sua trajetória pessoal) faz parte do processo de superação de traumas - processo que cada vez mais parece ter que se dar tanto no espaço público quanto na esfera privada. Esse consenso em torno da necessidade de documentar a história das vítimas - da perspectiva das vítimas e de seus familiares, e ainda no calor dos acontecimentos - já seria significativo por si só, ao menos do ponto de vista que importa para o presente artigo, centrado nos usos emergentes da história oral. Mas essas não foram as únicas iniciativas no campo da história oral relacionadas aos atentados. Uma busca no Google revela muitas outras, mais do que é possível contar, e que apresentam uma variedade quase inesgotável: são depoimentos (que se autodenominam de história oral) disponíveis na íntegra ou não, em vídeo, em áudio, fotografias, filmes, performances, profissionais e amadores, de anônimos e notórios. Muitos dos projetos oferecem, inclusive, a possibilidade de submissão (de depoimentos ou de outros materiais) espontânea online. Pode-se discutir a qualidade, a legitimidade, os critérios de cada um desses projetos, mas o fato é que sua mera existência nos força a pensar tanto os novos usos da história oral quanto a própria escala do fenômeno: há tantos que se torna uma massa difícil de manejar para uma pesquisa solitária.

Aqui, e a título de comparação, vale fazer um contraponto com outro projeto de proporções monumentais, a saber, a empreitada da Shoah Foundation para documentar a memória dos sobreviventes do holocausto. Esta última opera no registro do "resgate", ou seja, de coletar o maior número possível de histórias de vida antes que seus narradores morram, em condições controladas e de certo modo homogêneas, e de agrupá-las em um mesmo lugar. Isto é, a Shoah Foundation pode sofrer pelo excesso, mas o esforço é de esgotar e agrupar. A colaboração "espontânea" discutida aqui, por sua vez, mais se assemelha ao You Tube, com a possibilidade de jamais esgotar-se, e sofre ainda a fragmentação e a reiteração de outras iniciativas concorrentes. Assim, a proliferação de tais empreendimentos torna uma pesquisa mais qualitativa sobre as iniciativas que venho discutindo um trabalho extremamente árduo, senão impossível. Seria necessária uma equipe para monitorar e comparar os projetos, bem como a elaboração de uma metodologia própria. A questão passa a ser justamente como lidar com essa massa de informações. E, consequentemente, como os historiadores do futuro conseguirão lidar com essa enormidade de informações.

É claro que, por outro lado, não surpreende que os atentados terroristas de 11 de Setembro deem origem a tantos esforços memorialísticos. Afinal, além de a destruição sem precedentes de um dos lugares mais familiares de um certo imaginário midiático global ter sido testemunhada por todo o mundo em tempo real - seja pela grande mídia, seja pelo fato de ter sido documentada por incontá- 
veis câmeras amadoras (de turistas, moradores etc.) -, os atentados figuraram como um divisor de águas na autoimagem dos americanos. De fato, a transformação operada pelos atentados no imaginário social daquela nação, como poucos eventos, dá concretude à hipótese de Luc Boltanski (1993: 244-5) sobre como o colapso das utopias modernas teria feito com que deixássemos de ser uma humanidade conquistadora para nos tornarmos uma humanidade de vítimas.

No entanto, verificamos um fenômeno semelhante - guardadas as devidas proporções - no caso de outra grande catástrofe que marcou a história recente dos Estados Unidos, o furacão Katrina. Tanto os atentados terroristas quanto o furacão constituíram eventos traumáticos na memória coletiva dos norte-americanos, trazendo à tona realidades que vieram de encontro à sua velha autoimagem como um povo heroico. Basta digitar no Google "oral history katrina", e instantaneamente se é brindado com o que parece uma infinidade de projetos de história oral. Uma análise um pouco mais detida revela, no entanto, que são cerca de 20 projetos - comunitários, acadêmicos, militantes, e mesmo de performances e peças de teatro sobre a experiência do furacão elaboradas a partir de depoimentos de história oral. Como no caso dos atentados terroristas, a maior parte desses depoimentos foi colhida ainda nos primeiros meses após o fato.

Desses quase 20 projetos sobre o furacão Katrina disponíveis online até o momento, seleciono dois para discutir aqui. A escolha se dá pela ilustratividade de cada um das questões mais amplas e analíticas relativas ao uso da história oral levantadas ao longo deste texto, que por sua vez foram elaboradas a partir do impacto da própria imersão no material em questão. Tanto da perspectiva de cada site, quanto de um ponto de vista comparativo dos vários projetos, é fácil perceber que as entrevistas são muito reiterativas, a maior parte das pessoas vítimas indiretas ou testemunhas oculares - o que levanta a questão de um possível alargamento do que ou quem os pesquisadores/coordenadores de projetos consideram vítimas.

Assim, a primeira iniciativa em questão é o Hurricane Digital Memory Bank (http://www.hurricanearchive.org/), escolhido por constituir uma espécie de portal, abarcando vários subprojetos e coleções de "documentos" digitais (a maioria destes em áudio ou vídeo, sendo a maior parte depoimentos e imagens da devastação, mas incluindo também músicas, poemas, ou outras criações artísticas), mas sobretudo por seu caráter colaborativo. O projeto é coordenado pelo Center for History and New Media da Universidade George Mason e pela Universidade de Nova Orleans. O premiado projeto afirma constituir o maior arquivo público livre (com cerca de 25 mil itens em sua coleção) do Katrina (e também do furacão Rita, que atingiu a mesma região do país menos de um mês depois). Seu objetivo manifesto é "estimular alguns legados positivos ao permitir às pes- 
soas afetadas por essas tempestades contar suas histórias em suas próprias palavras, que como parte do registro histórico permanecerão acessíveis a uma grande audiência por gerações futuras".

Figura 1

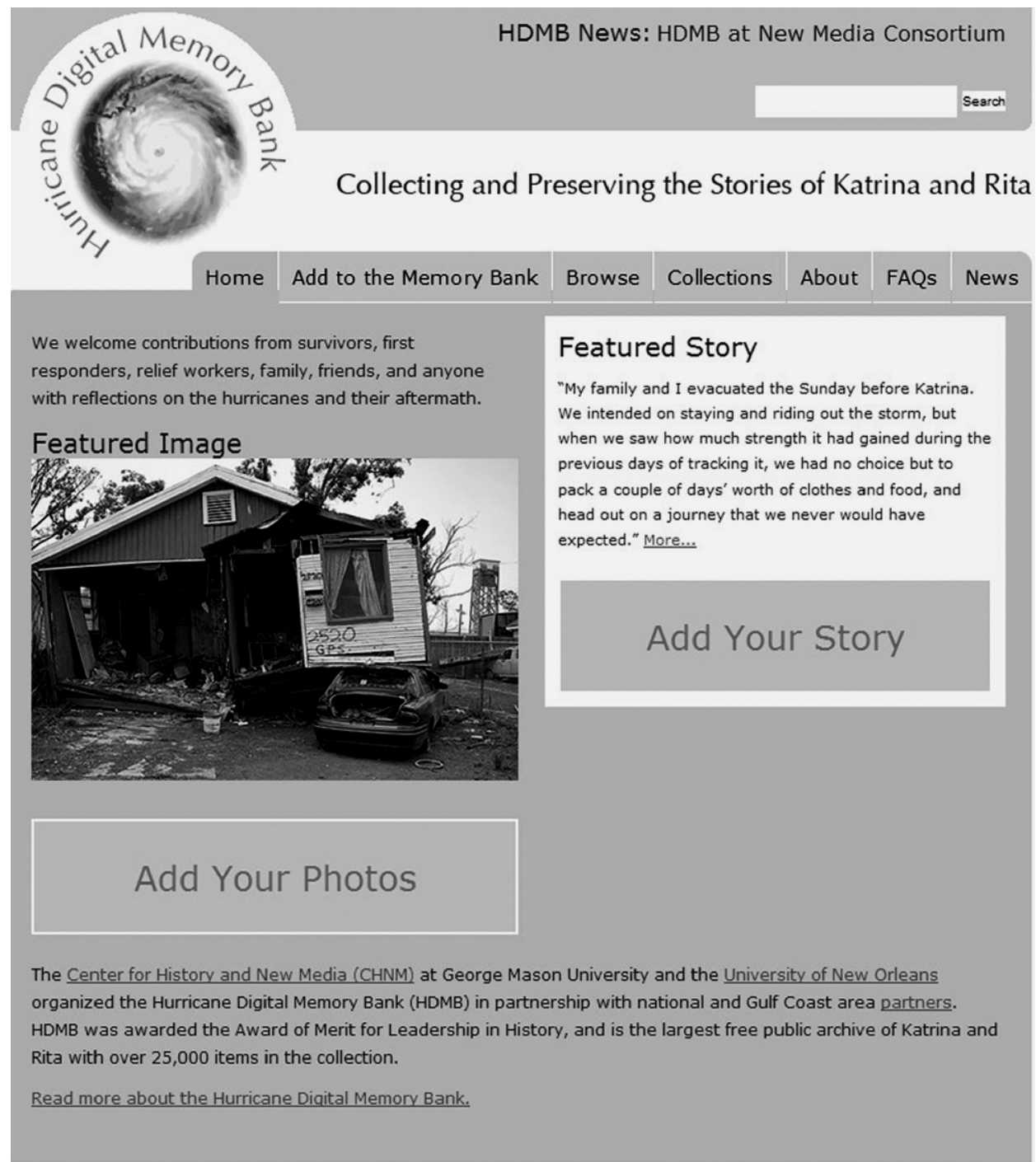

Copyrights for materials in the archive are retained by the original creators. All else (c) 2005 Center for History and New Media 
Logo em sua página inicial, se fazem presentes os três componentes principais do portal: há sempre uma imagem e as primeiras frases de um relato escrito em destaque - ambas vão se alternando a cada visita (ver figura 1). Abaixo de cada um desses itens há botões com as inscrições "Acrescente suas fotos" e "Acrescente sua história", que leva o espectador/potencial colaborador aos formulários específicos para contribuir da maneira que lhe convier (mesmo que não tenha sido vítima direta ou testemunha ocular). Não há qualquer espécie de triagem ou conferência do conteúdo ou da veracidade das informações; a aposta, explicitada na seção de perguntas frequentes e seguindo os preceitos da valorização da memória subjetiva, é que toda e qualquer contribuição constitui o registro histórico.

Embora essa seja uma afirmativa válida, diante dos 25 mil documentos audiovisuais - a maioria pouco memorável, e o conjunto extremamente reiterativo - é impossível não recordar um dos primeiros ensinamentos sobre uma pesquisa em história oral, encapsulado pelo conceito de "saturação", que aponta para o fato de que a proliferação desenfreada de entrevistas e relatos não necessariamente acrescenta ou acumula conhecimento, pois "há um momento em que as entrevistas acabam por se repetir, seja em seu conteúdo, seja na forma pela qual se constrói a narrativa" (Bertaux apud Alberti, 2004: 36-7). Essa ideia, no projeto em questão, parece irrelevante diante do ímpeto de igualar os relatos, de modo a não deixar de reconhecer nenhum sofrimento, nenhuma vítima.

Ainda que não seja este um projeto exclusivamente ancorado na história oral, o portal dá acesso a inúmeros projetos pontuais - muitos deles de história oral em um sentido mais estrito. Sua análise vale a pena sobretudo pela própria indiferenciação que atribui à especificidade da história oral. Uma crítica fácil a essas iniciativas consistiria em questionar se podem ser considerados, de fato, história oral - dada a disparidade de metodologias de coleta de dados e de realização de entrevistas. No entanto, essa crítica perde de vista o fato de os atores envolvidos afirmarem estar se valendo da metodologia da história oral. Ou seja, vale menos a pena discutir se a história oral que fazem é boa ou má do que tentarmos vislumbrar seus efeitos sobre as próprias concepções correntes do que é a história oral. Assinalo, portanto, sua significância como exemplo dos novos usos que venho discutindo pelo próprio fato de constituir a história oral como uma entre várias fontes para a construção de uma memória para a posteridade; por levar ao que os americanos gostam de se referir como o potencial democratizador da história oral às últimas consequências, através da incorporação dessa tendência de aceitar contribuições espontâneas; e, finalmente, por fazê-lo em um ambiente acadêmico, assim borrando as fronteiras outrora mais rígidas entre a história oral acadêmica e sua vertente militante. 
O segundo projeto que pretendo discutir aqui tem o objetivo não só de documentar a experiência do furacão para a posteridade, mas sobretudo o de fornecer subsídios para a formulação de políticas públicas futuras. Segundo o próprio site da iniciativa (http://www.hurricanekatrina.med.harvard.edu/), o Hurricane Katrina Community Advisory Group foi constituído com o objetivo de produzir o conhecimento necessário para que os responsáveis por políticas de governo "compreendam os problemas enfrentados pelos mais de seis milhões de pessoas [afetados pelo furacão] enquanto tentam reconstruir suas vidas". A premissa básica é a de que o melhor modo de realizar essa tarefa é através do "monitoramento, ao longo do tempo, de um grupo de pessoas que representam aqueles afetados pelo Katrina". O acompanhamento desse grupo representativo (que inclui amostras de residentes de todas as áreas atingidas pelo furacão) é feito através de entrevistas periódicas - algumas das quais de história oral segundo a definição do site - que fornecem os subsídios para a produção de relatórios e boletins para a imprensa. O projeto foi realizado pelo departamento de políticas de saúde da Escola de Medicina da Universidade de Harvard, e seu componente de história oral compreende 380 entrevistas realizadas pelo telefone entre janeiro e fevereiro de 2006 (ou seja, entre quatro e seis meses depois do furacão em si). As entrevistas se desdobram, com algumas variações, a partir de três perguntas. Às vezes beirando a entonação de operadores de telemarketing, grande parte das entrevistas começa pedindo que o entrevistado narre sua experiência do furacão desde o momento em que ouviu a notícia na mídia até hoje, pedindo que considere tanto os fatos quanto seus sentimentos e sensações durante e depois do furacão. A segunda pergunta é feita da mesma maneira por entrevistadores distintos, ainda que sua formulação seja seguida à risca: "Muitas pessoas testemunharam atos extraordinários de bondade e heroísmo da parte de estranhos completos. Algo assim lhe aconteceu?" A terceira e última pergunta dizia respeito ao presente: "Como está sua vida hoje?"

A escuta de diversas entrevistas assim estruturadas - e cujos entrevistados são identificados apenas por números que se assemelham a códigos de barra (ver figura 2) - permitiu identificar alguns elementos que se repetiam ao longo de entrevistas efetivamente diversas, mas que tornavam-se reiterativas: em primeiro lugar, demarca-se um início para o evento do furacão: o momento em que a mídia informa que a tempestade seria pior do que o esperado originalmente. Postula-se, como início da tragédia, um momento que pode ser compartilhado por muitos, fechando, assim, a possibilidade de outros marcos iniciais. As entrevistas são temáticas no sentido mais estrito do termo: os entrevistados são testemunhas, pura e simplesmente de um acontecimento que todos já conhecemos; suas biografias até então parecem não importar. O evento é, assim, provido de um recorte temporal unificado, quando sua experiência pode ter sido diversa. 
Figura 2

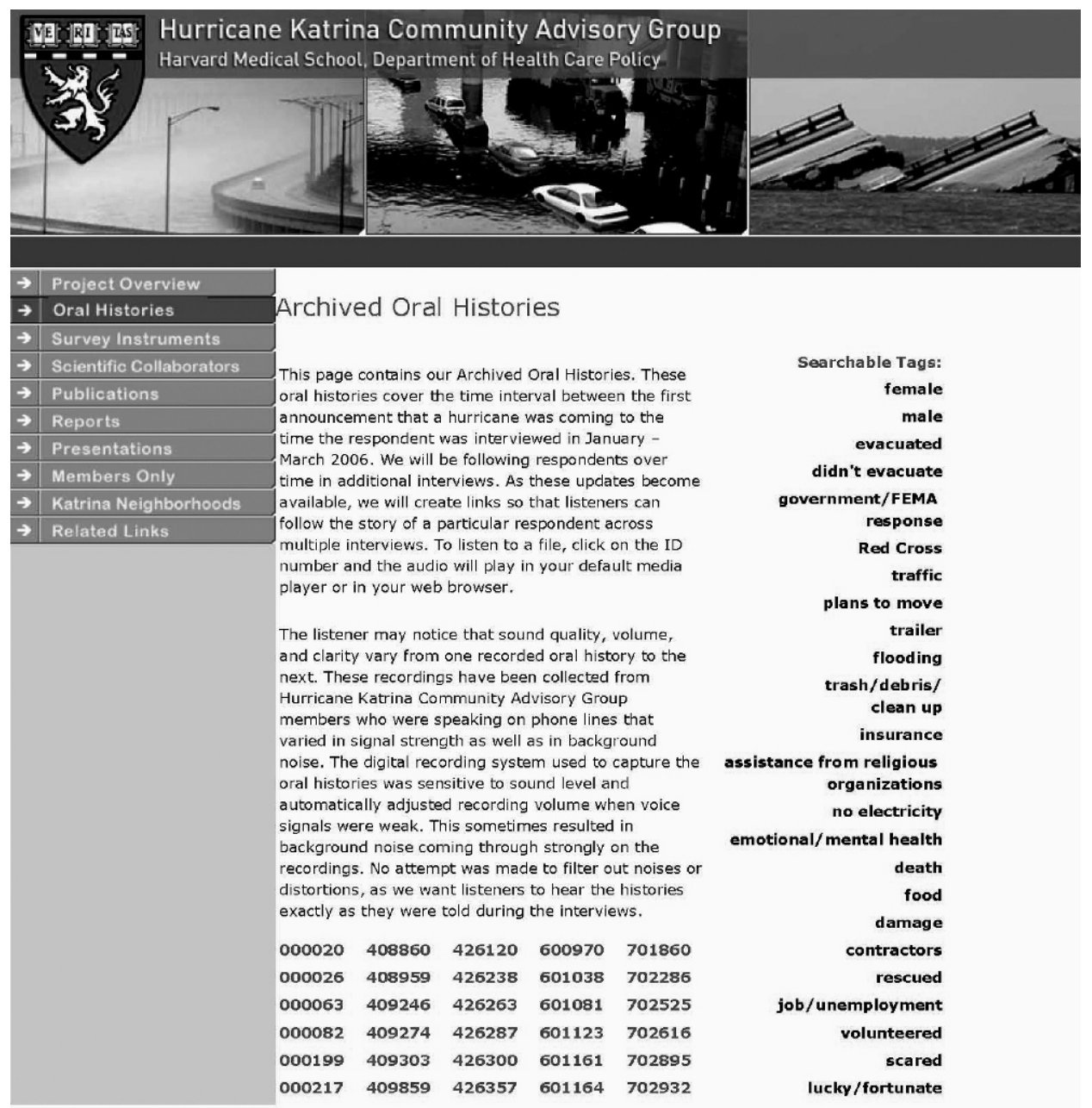

Esse movimento é reforçado pela segunda pergunta, a que indaga sobre o testemunho de atos de heroísmo. Ora, qualquer estudante de segundo período de jornalismo sabe que isso é conduzir uma entrevista (ainda que na prática da profissão muitos repórteres não façam outra coisa). Qualquer manual de história oral ou de qualquer outro tipo de entrevista alerta contra esse tipo de encaminhamento - não é sequer necessária a sofisticação de uma crítica pós-moderna ou de teorizações sobre lugares de fala e relações de poder no ato de entrevistar para identificar nesse tipo de pergunta uma redução da própria - o que é ainda mais 
grave se levamos em conta que essas entrevistas fazem parte de um esforço de elaboração de políticas públicas.

No caso específico do furacão Katrina, a condução da entrevista é ainda mais insidiosa. É sabido que a catástrofe resultou, de fato, da justaposição da tempestade em si com o rompimento do dique, e foi totalmente exacerbada pelos saques, pelo colapso da infra-estrutura urbana e o consequente caos social que seguiu. Assim, nas poucas entrevistas em que a "catástrofe humana" foi mencionada, apesar de todos esses entraves (e some-se a estes o fato de nenhuma dessas entrevistas extrapolar dez minutos), a inserção da segunda pergunta foi efetiva em desviar o testemunho para temas mais "positivos", e frisar a solidariedade em meio ao caos e ao desespero. Em suma, conforma-se assim toda uma pluralidade potencial de falas de experiências a uma narrativa semelhante àquela que emergiu nos Estados Unidos pós-11 de Setembro: a de um povo que, em momentos decisivos, demonstra seu lado mais solidário e heroico - "land of the free, home of the brave" - resiliente face às catástrofes (narrativa essa que a própria experiência do furacão negou, ao tornar dolorosamente evidente um país em que a questão da pobreza encontra-se ainda profundamente racializada e as desigualdades sociais tão frequentemente silenciadas irromperam no espaço público).

A pergunta sobre como os entrevistados estão hoje também conduz as narrativas: se o furacão tem um começo socialmente compartilhado (i.e., sua veiculação na mídia), como evento na biografia individual ele constitui-se como processo traumático que ainda não se esgotou, e cujas vítimas continuam sofrendo. Ou essa é a premissa da qual se parte, mais uma vez produzindo um eixo narrativo unívoco, em detrimento de outras narrativas possíveis. $O$ furacão é elaborado, assim, como um evento com começo, mas sem fim.

\section{Conclusão}

Para além dos diferentes meios e formatos, parece haver algo de realmente novo em termos das implicações sociais das condições de produção desses arquivos. Temos o caso de uma produção de memória para o futuro, em "tempo real", em que os testemunhos já são dados tendo em vista uma narrativa histórica, ou que pretende vir a ser histórica - e seus possíveis usos políticos. O testemunho é aqui pensado, coletado e disponibilizado tendo em vista um reconhecimento não mais como antídoto (como no caso das lutas pelo reconhecimento ou do dever de memória), mas como profilático para o esquecimento. Cristalizam-se, assim, certas narrativas (como, por exemplo, a dos heróis anônimos que irrompem em momentos difíceis) em detrimento de outras, que acabem silenciadas (como, por exemplo, os saques, a violência, a própria questão racial). 
Essa operação de silenciamento, paradoxalmente, só é possível tendo em vista a considerável legitimidade da história oral como metodologia de produção de conhecimento, bem como da valorização contemporânea do testemunho das vítimas (especialmente essa colhida no calor dos eventos). E essa parece ser uma tendência em vias de consolidação, se levamos em conta uma das poucas iniciativas de financiamento de pesquisas exclusivamente no campo da história oral nos Estados Unidos, o Emerging Crises Research Fund. ${ }^{11}$ Onde houver catástrofe, parece, haverá, além dos jornalistas de praxe, uma enxurrada de praticantes acadêmicos e militantes da história oral com seus gravadores e câmeras de vídeo. E esse é um aspecto da prática contemporânea da história oral que não tem sido discutido na mesma escala em que se consolida (uma exceção, que versa também sobre o Katrina, porém de uma perspectiva acrítica, pode ser encontrada em Sloan, 2008). A essa produção juntar-se-ão, inevitavelmente, os vídeos amadores, contribuições espontâneas, e entrevistas de execução questionável que povoam esses "You Tubes" especializados em catástrofes.

Seria, talvez, um alento termos o luxo de atribuir essa produção desenfreada a uma excentricidade norte-americana, mais um traço das idiossincrasias que beiram o caricato do império cultural em tempos de globalização. No entanto, a proliferação de investimentos comunitários na produção de suas memórias nos EUA faz parte de um mesmo movimento global de redefinição das relações entre memória e identidade, e em particular da politização de identidades sociais e pessoais, sobretudo aquelas outrora "privadas" e hoje construídas no espaço público como identidades de vítimas - e o consequente lugar de fala legitimador do discurso de vítimas nesse espaço público.

Aqui, vale um contraponto com o caso do "devoir de mémoire" na França contemporânea, tal como analisado por Heymann (2007) em artigo recente. Em jogo, nos dois casos, está o reconhecimento de sofrimento de vítimas, que acabam por constituir suas identidades no espaço público enquanto vítimas. No entanto, no caso francês, as demandas das vítimas tinham como objetivo questionar uma narrativa até então hegemônica, atravessada por relações de poder que haviam produzido a própria vitimização. Ou seja, produzir uma narrativa de memória e reparar danos históricos. Há, portanto, uma temporalidade do "antes tarde do que nunca", um movimento de abertura para o futuro, e uma discussão acerca da relação entre memória e esquecimento. A questão, aqui, é que essa identidade de vítima torna-se um idioma através do qual eventos traumáticos são experimentados e processados; isto é, a vitimização produz o sentido dos eventos, e não o contrário. Em última instância, banaliza-se a própria condição de vítima e reproduz-se o jogo de silêncios e apagamentos que gera movimentos como o próprio devoir de mémoire.

Esse panorama de simultânea legitimação sem precedentes e potencial banalização da narrativa de história oral engendra uma série de novos desafios 
éticos, e levanta mais questões do que respostas, que não pude chegar perto de esgotar neste breve trabalho. Encerro, portanto, com duas perguntas: quais são as implicações - teóricas, metodológicas, políticas e éticas - dessa nova temporalidade da construção da memória para a teoria e a prática da história oral? Como interpretar e encontrar sentido diante dessa polifonia de informações - e de vítimas - disponíveis online?

Notas

\section{Cf. <http://www.h-net.org/oralhist/>.}

2. As traduções desta troca de emails, bem como dos conteúdos dos sites analisados neste artigo, são todas minhas.

3. $\mathrm{O}$ artigo ao qual se refere é Mixed martial arts and masculinity: a case study in treating internet sources as oral history, Oral History vol. 35, n. 2, Autumn, p. 91-99.

4. Cito aqui a segunda edição de 1985 . No entanto, a primeira edição do livro é de 75 .

5. Um excelente debate, por exemplo, encontra-se no volume 34 da revista The Oral History Review, a partir de um artigo de Alistair Thomson (2007a) que gerou, na edição seguinte, um comentário do próprio Grele (2007), seguido por tréplica de Thomson (2007b).

6. Nisso, evoca o texto já clássico em antropologia Europe and the people without history, de Eric Wolf (1982), que brinca justamente com a geografia imaginária de um imperialismo que situa o começo da história dos povos ditos primitivos a partir do encontro colonial. Sabemos, no entanto, que longe do mundo anglosaxão, a história oral já encontrava-se bastante institucionalizada, inclusive do ponto de vista da formação de redes de pesquisadores cuja atuação passava ao largo da academia norte-americana. Para um relato dessa trajetória do ponto de vista do Brasil, cf. Ferreira (2000).

7. A cientista política e feminista Wendy Brown (1995) constrói uma crítica desse lugar de fala a partir do conceito nietzscheano de ressentimento. Seu objetivo é problematizar a legitimidade $a$ priori da vítima ao denunciar que essas dinâmicas de fato fixam a identidade da vítima, gerando desejos de vingança como o único modo de reparação.

\section{A definição do novo programa - como} consta do site - o descreve como "mestrado no campo da história oral focado em metodologias de entrevistas e métodos interpretativos". O curso frisa sua interdisciplinaridade, ao afirmar conectar pesquisas em ciências sociais e humanidades através de seis disciplinas: história, sociologia, literatura, antropologia, psicologia e saúde pública. Suas aplicações práticas são: preservação histórica, produção de rádio, escrita, e direitos humanos e legais. É interessante notar que, ainda que permaneça "na ponta" em termos de avanços nessa história oral mais reflexiva, mais acadêmica - tanto que seu último instituto de verão teve como tema História Oral, Militância e Leis -, sua abordagem em termos de produtos e sua entrada nesse mundo multimidia permanece um tanto "clássica". Apesar de o programa de 
Columbia ter recentemente reformulado seu site, este não disponibiliza materiais online, seja em áudio, seja em texto - e, na verdade, não está claro sequer se já se aventurou de modo mais sistemático no campo do audiovisual.

9. A necessidade de se nomear individualmente as vítimas de grandes eventos traumáticos surge, pela primeira vez, nas discussões em torno da memória das vítimas do holocausto.

\section{Referências bibliográficas}

ALBERTI, Verena. 2004. Manual de história oral. $2^{\mathrm{a}}$ versão revista e atualizada. Rio de Janeiro: FGV.

BOLTANSKI, Luc. 1993. La suffrance à distance. Paris: Metalié.

BROWN, Wendy. 1995. States of injury: power and freedom in late modernity. Princeton: Princeton University Press.

FERREIRA, Marieta de M. 2001. Entrevista com Marieta de Moraes Ferreira. História Oral, São Paulo, n. 4, jun., p. 165-176.

GRELE, Ronald J. 1985. Envelopes of sound: the art of oral history. Chicago: Precedent Publishing, Inc. 2007. Commentary. The Oral History Review, vol. 34, n. 2, p. 121-124.

GLUCK, Sherna Berger; RITCHIE, Donald A.; EYNON, Bret. 1999. Reflections on oral history in the new millenium: roundtable comments. The Oral History Review, vol. 26, n. 2, p. 1-27.

HEYMANN, Luciana. 2007. O "devoir de mémoire" na França contemporânea: entre memória, história, legislação e
10. Do mesmo modo, o Corpo de Bombeiros de Nova York começou a coletar entrevistas ainda nos primeiros dias de outubro de 2001.

11. Há, também, um fio de discussão na já referida lista $\mathrm{H}$-Net Oral-Hist sobre outros eventos em que foram colhidos depoimentos. São citados os terremotos na cidade do México em 1985 e na Armênia em 1988.

direitos. In: GOMES, Ângela de Castro (org.). Direitos e cidadania: memória, política e cultura. Rio de Janeiro: FGV. p. 15-43.

HOPTON, John. 1999. Mixed martial arts and masculinity: a case study in treating internet sources as oral history. Oral History, vol. 35, n. 2, Autumn, p. 91-99.

HUYSSEN, Andreas. 2000. Seduzidos pela memória: arquitetura, monumentos, mídia. Rio de Janeiro: Aeroplano.

JELIN, Elizabeth. 2002. Los trabajos de la memoria. Madri e Buenos Aires: Siglo Vientiuno.

PASSERINI, Luisa. 1987. Fascism in popular memory: the cultural experience of the Turin working class. Cambridge: Cambridge University Press.

PEREIRA, Vinicus. A. 2006. Marshall McLuhan, o conceito de determinismo tecnológico e os estudos dos meios de comunicação contemporâneos. Unirevista, vol. 1, n. 3 .

PORTELLI, Alessandro. 1991. The death of Luigi Trastulli and other stories: form 
and meaning in oral history. Albany, NY: State University of New York Press.

SARLO, Beatriz. 2007. Tempo passado: cultura da memória e guinada subjetiva. São Paulo: Cia. das Letras; Belo Horizonte: EdUFMG.

SHARPLESS, Rebecca. 2006. The history of oral history. In: CHARLTON, Thomas L.; MYERS, Lois E.; SHARPLESS, Rebecca (eds.). Handbook of oral history. Lanham, MD: AltaMira Press.

SIBILIA, Paula. 2008. O show do eu: a intimidade como espetáculo. $1^{\mathrm{a}}$ ed. Rio de Janeiro: Nova Fronteira.

2003. Os diários íntimos na internet e a crise da interioridade psicológica. In: LEMOS, André; CUNHA, Paulo (orgs.). Olhares sobre a cibercultura. Porto Alegre: Sulina. p. 139-152.

SLOAN, Stephen. 2008. Oral history and hurricane Katrina: reflections on shouts and silences. Oral History Review, n. 27 [Advance Access published June 26].

SMITH, Merritt R.; MARX, Leo (eds.). 1994. Does technology drive history? The dilemma of technological determinism. Cambridge: MIT Press.

TAYLOR, Charles. 1992. Multiculturalism and "The Politics of Recognition". Princeton: Princeton University Press.

THOMSON, Alistair. 2007a. Four paradigm transformations in oral history (1). The Oral History Review, vol. 34, n. 1, p. 49-70.

2007b. Response. The Oral History Review, vol. 34, n. 2. p. 125-128.

TREBISCH, Michel. 1994. A função epistemológica e ideológica da história oral no discurso da história contemporânea. In: FERREIRA, Marieta de Moraes (org.). História oral e multidisciplinaridade. Rio de Janeiro: Diadorim. p. 19-44.

VAZ, Paulo. 2004. Esperança e excesso. In: PARENTE, André (org.). Tramas da rede. Porto Alegre: Sulina. p. 189-208.

WOLF, Eric. 1982. Europe and the people without history. Berkeley: University of California Press.

Seleção de sites consultados (acessados pela última vez em 21/12/2008)

http://www.hurricanearchive.org/ Hurricane Digital Memory Bank

http://www.hurricanekatrina.med.harvar d.edu/oralhistories-archives.php Hurricane Katrina Community Advisory Group

http://graphics8.nytimes.com/packages/ $\mathrm{html} /$ nyregion/20050812_WTC_GRAPH IC/met WTC histories full_01.html Oral Histories from Sept. $\overline{1} 1$ compiled by the New York Fire Department

http://www.columbia.edu/cu/lweb/indiv/ oral/sept11.html

September 11 Oral History Projects -

Columbia University Oral History Research Office

http://www.ashp.cuny.edu/febr2002.htm American Social History Project, The September 11 Digital Archive

http://www.npach.org/k-r.htm National policy and advocacy council on homelessness

http://www.usm.edu/afterkatrina/ After Katrina Newswire

http://aliveintruth.org/

The New Orleans Disaster Oral History and Memory Project

http://www.ijdesign.com/thegreatdeluge/ Oral_History_Project.php

The Great Deluge Oral History Project

http://www.library.unlv.edu/oral_hisrorie s/addl_pages/katrina.html 
Oral History Research Center, University of Nevada, Las Vegas.

http://thekatrinaexperience.net/

The Katrina Experience - an Oral History

Project

http://katrina.jwa.org/

Katrina's Fewish Voices - an online collecting project of the Fewish Women's Archive

http://www.newyorknighttrain.com/zine/ issues/3/oralhist.html
New Orleans Ninth Ward Underground Katrina Oral History Project by New York Night Train

http://www.loyno.edu/ rrkr/intro.htm Religious Responses to Katrina and Rita: $A$ Loyola University of New Orleans oral history project.

http://www.uscg.mil/history/katrina/katri naoralhistoryindex.asp

US Coast Guard Oral History Program

\section{Resumo}

$\mathrm{O}$ artigo discute algumas implicações políticas de novos usos e apropriações da metodologia da história oral, possibilitados pela disseminação das mídias digitais. A partir da análise de projetos centrados em testemunhos das vítimas da devastação causada pelo furacão Katrina, desenvolvidos em grandes universidades norte-americanas, o artigo elabora dois aspectos da produção e disseminação destes testemunhos: primeiro, as apropriações contemporâneas da história oral para a construção política de memórias deliberadamente produzidas tendo em vista a consolidação de narrativas hegemônicas futuras; segundo, como a própria proliferação destas iniciativas vem gerando, simultaneamente, a multiplicação de vítimas, e a fragmentação e dispersão de seus testemunhos. Palavras-chave: memória, história oral, furacão Katrina, mídias digitais, vítimas

\section{Abstract}

The article discusses how the diffusion of digital media has engendered new usages and appropriations of oral history, as well as the political implication thus entailed. By analyzing projects centered on the testimonies of victims of the devastation brought about by hurricane Katrina and developed in large American universities, the article elaborates two aspects of the production and diffusion of these testimonies: first, how contemporary appropriations of the oral history methodology lend themselves to the deliberate construction of future hegemonic memories; second, how the very proliferation of such endeavors promotes simultaneously a proliferation of victims and the fragmentation and dispersal of their testimonies.

Key words: memory, oral history, hurricane Katrina, digital media, victims 


\section{Résumé}

Larticle discute les implications politiques des nouveaux usages et appropriations de la méthodologie de l'histoire orale possibilités par la dissémination des midia digitales. À partir de l'analyse de projets centrés autour des témoignages des victimes de l'ouragan Katrina développés dans des grandes universités américaines, l'article analyse deux aspects de la production et la dissémination de ces témoignages: d'abord, les appropriations contemporaines de l'histoire orale pour la construction politique de mémoires délibérément produites ayant en vue la consolidation de récits hégémoniques futurs; deuxièmement, la façon dont la prolifération de ces initiatives est en train de produire simultanément la multiplication de victimes e la fragmentation et dispersion de leurs témoignages.

Mots-clés: mémoire, histoire orale, ouragan Katrina, midia digitales, victimes 